\title{
U.S. Frontier Distribution of Advanced Practice Registered Nurses and Population Health
}

\author{
Lynn Jakobs, PhD, FNP-c ${ }^{1}$ \\ Jeri Bigbee, PhD, RN, FAAN ${ }^{2}$
}

\author{
${ }^{1}$ Clinical Instructor, College of Nursing and Professional Disciplines, Nurse Practitioner \\ Program, University of North Dakota, lynnjakobs@hotmail.com \\ ${ }^{2}$ Adjunct Professor, Betty Irene Moore School of Nursing, University of California, Davis, \\ jlbigbee@,ucdavis.edu
}

\begin{abstract}
Residents of frontier counties have disparate access to healthcare due to geographic and economic factors that impact the availability of health care providers and services. The purpose of this study was to evaluate the distribution of Advanced Practice Registered Nurses (APRNS) in U.S. frontier counties and to evaluate the relationship between the presence of APRNs and population health outcomes those counties. The sample included data from 308 frontier counties in 14 states and 858 licensed APRNs residing in those counties. This cross-sectional ecological comparative study utilized the concept of nurse dose to evaluate the relationship between the presence of APRNs and population health outcomes in frontier counties. Findings include significantly lower premature death and teen birth rates in frontier counties where APRNs or physicians are present.

Keywords: Frontier, Advanced practice nurses, Rural/remote
\end{abstract}




\section{U.S. Frontier Distribution of Advanced Practice Registered Nurses and Population Health}

According to 2010 data provided by the state departments of rural health, over five million people live in remote areas of the United States (US) that are classified as frontier (Rural Health Information Hub). In these areas access to healthcare, or services of any kind, is often limited by extreme distances and travel time. According to the last known figures, the majority of frontier counties have two or fewer health services of any type and as many as a quarter million people may be living in frontier counties with no available health services (Frontier Education Center, 2000).

Disparate access to rural healthcare has been a federal concern since the early 1970's. With passage of the Medicare bill in July 1965, the federal government assumed a responsibility for the healthcare coverage of older Americans regardless of geographic residence. Rural underserved Medicare recipients had limited access to healthcare, therefore, the Rural Health Clinic Act of 1977 was passed to incentivize rural practice and increase access to care. This act authorized Medicare and Medicaid payments to qualified rural clinics for services provided by nurse practitioners (one of the four categories of advanced practice registered nurses) and promoted their use by mandating that at least $50 \%$ of the services in rural health clinics be provided by nurse practitioners or physician assistants (Department of Health and Human Services, 2013). The traditional APRN roles are nurse practitioner, certified registered nurse anesthetist, clinical nurse specialists, and certified nurse-midwife. In 1991, to further incentivize nurse practitioners (NPs) to practice in frontier and other underserved areas, the National Health Service Corps (NHSC), the largest public program addressing the geographic maldistribution of the U.S. healthcare workforce, added NPs and certified nurse midwives (one of the four categories of advanced practice nurse) to their student loan repayment program (Earle-Richardson \& Earle-Richardson, 1998). To benefit 
from this program advanced practice registered nurses (APRNs) agree to practice in a designated healthcare professional shortage area for a minimum of two years. In 2009, this program was bolstered by the American Recovery and Reinvestment Act which allotted a $\$ 300$ million supplement to the NHSC. During the Recovery Act period, March 2009 through February 2011, the increase in numbers of nurse practitioners recruited was proportionately higher than all other healthcare professionals (Pathman \& Konrad, 2012).

Despite Federal incentives to encourage frontier APRN practice studies have shown that only a fraction of APRNs are practicing in frontier or other underserved areas (Kaplan, Skillman, Fordyce, McMenamin, \& Doescher, 2012). In the year 2000, the last year that a national survey of APRNs was conducted, data on nurse practitioners indicated that approximately $15.2 \%$ were practicing in rural areas with only $2.5 \%$ of all nurse practitioners practicing in frontier areas (Kaplan et al., 2012). Although efforts to recruit APRNs to frontier areas continue, little is known about the population health effects in frontier counties where APRNs practice.

This study utilized a census-based method of defining a frontier county; one with a population density of less than seven persons per square mile (Ricketts, Johnson-Webb, \& Taylor, 1998). According to the National Center for Frontier Communities (NCFFC), in 2010 there were 486 unique frontier counties in the continental United States. States with the most frontier counties were: Colorado, Idaho, Kansas, Minnesota, Montana, Nebraska, North Dakota, New Mexico, Oklahoma, South Dakota, and Texas.

\section{Demographics}

Federal lands comprise approximately $48 \%$ of the acreage of the 11 western states and the majority of frontier land is under federal stewardship (Lorah, 2000). Seventy-seven percent of all non-metropolitan federal land counties are found in the frontier, and $23 \%$ of frontier counties 
consist largely of only federal land (Frontier Education Center, 2000). Key frontier industries include farming/ranching, mining, forestry and oil, gas and mineral extraction. The majority of tribal land continues to be located in frontier areas; however, frontier communities are becoming more ethnically diverse owing to regional migration patterns. During the 1990s and post-2000 period, the rural Hispanic population grew at the fastest rate of any racial or ethnic group while the White population grew at the slowest rate (Johnson, 2006). The frontier population is also aging; since 2010, the increase in birth rate (natural change) has not matched the rate of outmigration (U.S. Department of Agriculture, Economic Research Service [USDA], 2015).

Current evidence suggests that health status declines with increasing rurality (Singh \& Siahpush, 2014). Health outcomes are worse in rural/frontier areas for patients with conditions that account for a large percentage of early deaths, i.e. heart disease, (Bhuyan, Wang, Opoku, \& Lin, 2013; Kulshreshtha, Goyal, Veledar, \& Vaccarino, 2014) cancer, (Nguyen-Pham, Leung, \& McLaughlin, 2014; Singh, 2012; Weaver, Geiger, Lu, \& Case, 2013), diabetes, (Hale, Bennett, \& Probst, 2010) and chronic obstructive pulmonary disease (Jackson, Coultas, Suzuki, Singh, \& Bae, 2013). Obesity rates are higher in rural areas (Befort, Nazir, \& Perri, 2012), and rural/frontier residents may be less likely to receive preventive care; from 1998-2005, frontier residents had the overall lowest screening rates for colo-rectal cancer when compared to other demographic groups (Cole, Jackson, \& Doescher, 2012). In the most isolated frontier areas, $78.7 \%$ of women travel at least 60 minutes to the nearest hospital offering perinatal services (Rayburn, Richards, \& Elwell, 2012), and are significantly less likely to receive counseling related to smoking, alcohol/drug use, and contraception (McCall-Hosenfeld \& Weisman, 2011). The rates for unintentional injuries, which include motor vehicle accidents, and suicide, are much higher in rural/frontier areas than in urbanized areas (Singh, Azuine, Siahpush, \& Kogan, 2013). 
Despite the limited resources and health disparities in frontier areas, there are positive attributes that may enhance health. Frontier communities are often located in some of the most beautiful settings in the world. Residents tend to be close-knit, the air is clean, there are bountiful resources, and low crime rates (Brown \& Schafft, 2011; Jones, Fly, Talley, \& Cordell, 2003; McGranahan, 2003; Monk, 2007; Wells \& Weisheit, 2004; Wood, 2008). Although frontier dwellers have an increased risk for multiple morbidities, social support and self-management practices are evident in these communities, reflecting a culture of self-sufficiency (Bardach, Tarasenko, \& Schoenberg, 2011)

\section{Conceptual Framework}

This study builds on the concept of nurse dose which includes three components: dose, nurse, and host response (Brooten \& Youngblut, 2006; Brooten, Youngblut, Deosires, Singhala, \& Guido-Sanz, 2012). The underlying assumption of this framework is that specific nurse characteristics (experience, expertise, and education), along with the number of nurses in a setting, are related to the overall health of their community. This concept has been useful in measuring the effects of registered nurses (RNs) as well as APRNs (Brooten et al., 2012; Brooten, Youngblut, Kutcher, \& Bobo, 2004). This study evaluated the relationship between the advanced education and clinical expertise of APRNs (nurse), as well as the presence or absence of APRNs (dose), and the population's health in frontier counties (host response).

The purpose of this study was twofold: to evaluate the distribution of APRNs in U.S. frontier counties and to evaluate the relationship between the presence of APRNs and population health outcomes in U.S. frontier counties. The research questions were: What is the workforce distribution of APRNs in U.S. frontier counties? Is there a mean difference in population health 
outcomes in U.S. frontier counties where APRNs are present compared to U.S. frontier counties where APRNs are not present?

\section{Method}

A cross-sectional, ecological, comparative study was conducted utilizing a secondary analysis of existing national data. The data were compiled as part of the Nurses and the Population's Health Study funded by the National Council of State Boards of Nursing Center for Regulatory Excellence (Bigbee, Evans, Lind, Perez, Jacobo \& Geraghty, 2014). Advanced practice registered nurse is defined as: nurse practitioner, certified registered nurse anesthetist, certified nurse-midwife, clinical nurse specialist (Stasa, Cashin, Buckley, \& Donoghue, 2014). Information regarding APRN numbers by county of residence in 2013 was obtained directly from 14 state boards of nursing while physician numbers in each county were obtained from the 2012 County Health Rankings (CHR) database (University of Wisconsin, 2012). State boards of nursing do not differentiate between the four types of APRNs when reporting numbers of APRNs in each county. It is the assumption of the researchers in this study that APRNs practicing in the frontier are more likely to be primary care APRNs, such as nurse practitioners.

Health outcome data were also obtained from the 2012 CHR database in which a variety of health indices are used to describe the current health status in most U.S. counties. Counties within each state are ranked utilizing a weighted summary of several measures: health outcomes (based on an equal weighting of mortality and morbidity measures), health factors (including health behaviors), and the physical environment (environmental quality and the built environment). A complete description of all indices, data sources, and measures included in the CHR is available at www.countyhealthrankings.org/Our-Approach. To allow for comparative analysis between frontier counties in multiple states only raw health outcome and health factor data were utilized. 
This study evaluated the relationship of APRN presence and the most consistently reported frontier county health indices: premature death rate (mortality); the percentage of low birth weight births; sexually transmitted infection rates (STI); and adult smoking rates. The dataset included information from 308 frontier counties in 14 states: California, Idaho, Louisiana, Maine, Minnesota, Montana, North Dakota, Nebraska, New Mexico, Nevada, Oregon, South Dakota, Texas, and Wyoming (Figure 1). It also included information on 858 licensed APRNs residing in frontier counties in those states. Population health indices in counties with APRNs $(n=215)$ were compared to those counties without APRNs $(\mathrm{n}=94)$ using $t$-test analyses. It should be noted that population health data were not reported consistently for the frontier counties in this study.

The data were analyzed using SPSS (version 22.0). Descriptive statistics were computed for the counties including APRN distribution as well as APRN and physician numbers per county. The descriptive analysis was supplemented with visualization through the use of Geographic Information Systems (GIS) analysis (ArcMap version 10.2.1.3497, ESRI, Redlands, CA). 


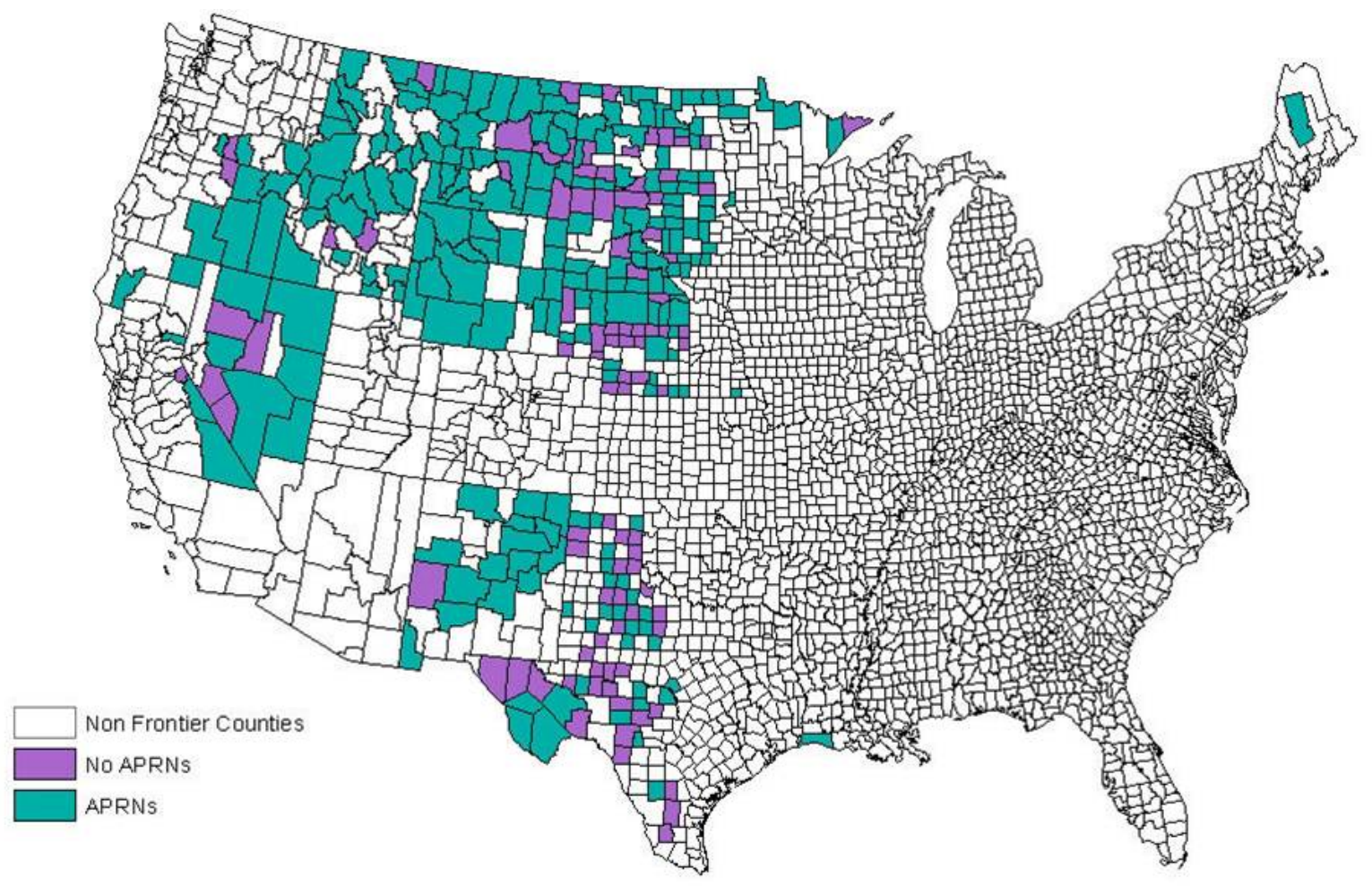

Figure 1. Map of continental U.S. counties

${ }^{\text {a }}$ Frontier counties included in this study are color-coded.

\section{Results}

The diversity of the frontier counties included in this study is reflected in the descriptive findings as illustrated in Table 1. There was considerably more variability in the number of physicians per county compared to the number of APRNs. The wide range in the numbers of both APRNs and physicians per county may indicate the presence of population centers within larger frontier counties. Of the 308 frontier counties included in this study all had at least one RN and 215 had at least one APRN. 
Table 1

Frontier County Descriptive Findings

\begin{tabular}{llccr}
\hline \multicolumn{1}{c}{ Variable } & N & Mean & SD & \multicolumn{1}{c}{ Range } \\
\hline APRNs & 215 & 2.79 & 4.03 & $0-29$ \\
Primary Care Physicians & 232 & 7.08 & 8.46 & $0-51$ \\
$\begin{array}{l}\text { Population Density (persons/square mile) } \\
\text { Square Miles }\end{array}$ & 308 & 3.08 & 1.78 & $0.2-6.9$ \\
& 308 & 2,292 & 2,336 & \multicolumn{1}{c}{$431-$} \\
& & & & 18,181 \\
\hline
\end{tabular}

Table 2 lists the distribution of APRNs in this study by state of residence. States with the highest number of frontier APRNs were: Wyoming, Montana, and New Mexico. According to census data, in 2010 the population per square miles in those states was: 5.8, 6.8, and 17. States with the lowest number of frontier APRNs were: Louisiana, Maine, and Minnesota. The population per square miles in those states was: 104.9, 43.1, and 66.6.

Table 2

Distribution of APRNs in Frontier Counties by State

\begin{tabular}{lccc}
\hline State & \# Frontier Counties & $\begin{array}{c}\text { \# Frontier Counties } \\
\text { with APRNs }\end{array}$ & \#APRNs \\
\hline CA & 6 & 5 & 42 \\
ID & 16 & 14 & 31 \\
LA & 1 & 1 & 6 \\
ME & 1 & 1 & 15 \\
MN & 7 & 6 & 21 \\
MT & 45 & 38 & 189 \\
ND & 38 & 26 & 79 \\
NE & 39 & 19 & 44 \\
NM & 16 & 15 & 102 \\
NV & 10 & 6 & 24 \\
OR & 10 & 8 & 31 \\
SD & 38 & 30 & 72 \\
TX & 64 & 29 & 50 \\
WY & 17 & 17 & 120 \\
\hline
\end{tabular}


As noted above, not all frontier counties in the study reported population outcomes.

Among those counties with available data, independent $t$ - testing revealed several significant differences. As illustrated in Table 3, a significantly lower premature death rate, a significantly lower teen birth rate, and a significantly higher STI rate were found in counties with APRNs compared to counties without APRNs. No significant differences were found in relation to the adult smoking rates and the percentage of low birth weight babies.

Table 3

Comparison of Health Outcomes / Behaviors in Frontier Counties With and Without APRNs

\begin{tabular}{|c|c|c|c|c|c|}
\hline Outcome & $\mathbf{n}$ & Mean & SD & $t(d f)$ & $\mathbf{P}$ \\
\hline \multicolumn{6}{|c|}{ Premature Death } \\
\hline APRNs & 121 & 8867.87 & 3248.18 & \multirow{2}{*}{$3.14(136)$} & \multirow{2}{*}{$.002 *$} \\
\hline No APRNs & 17 & 11712.74 & 4959.57 & & \\
\hline \multicolumn{6}{|c|}{ Teen Birth Rate } \\
\hline APRNs & 153 & 45.50 & 22.73 & \multirow{2}{*}{$4.07(188)$} & \multirow{2}{*}{$.000 *$} \\
\hline No APRNs & 37 & 63.40 & 28.87 & & \\
\hline \multicolumn{6}{|c|}{ Sexually Transmitted Infection Rate } \\
\hline APRNs & 214 & 227.68 & 309.55 & \multirow{2}{*}{$-2.49(306)$} & \multirow{2}{*}{$.013^{*}$} \\
\hline No APRNs & 94 & 138.89 & 232.21 & & \\
\hline \multicolumn{6}{|c|}{ \% Low Birth Weight } \\
\hline APRNs & 140 & 7.70 & 1.67 & \multirow{2}{*}{$1.47(167)$} & \multirow{2}{*}{.144} \\
\hline No APRNs & 29 & 8.19 & 1.53 & & \\
\hline \multicolumn{6}{|c|}{$\%$ Adult Smoking } \\
\hline APRNs & 169 & 18.68 & 6.25 & \multirow{2}{*}{$.695(210)$} & \multirow{2}{*}{.488} \\
\hline No APRNs & 43 & 17.90 & 7.71 & & \\
\hline
\end{tabular}

${ }^{\mathrm{b}}$ Asterisk indicates 2-tailed significance.

\section{Discussion}

Nearly $20 \%$ of the frontier counties $(n=308)$ in this study reported no licensed APRNs or primary care physicians residing in those communities. This finding is consistent with a report by the Frontier Education Center (2000), which found there were no health services available in as many as 78 frontier counties spread over 21 states. APRNs and primary care physicians were fairly evenly distributed over the remaining 248 counties in the study. Of the 33 frontier counties 
that reported no APRNs, 16 were in Texas. Texas and Nebraska were the only states with more than $50 \%$ of frontier counties without APRNs. At the time of data collection both states had restricted APRN practice (Kaplan, Skillman, Fordyce, McMenamin \& Doescher, 2012). Nebraska has since acquired autonomous APRN practice while Texas is one of 13 states which still require physician delegation/supervision of APRN practice (American Association of Nurse Practitioners, 2016). This would indicate that the ability to practice autonomously may be an incentive for APRNs to locate to frontier counties in those states that allow it.

Many of the disparities in the health status of frontier residents may be attributed, at least in part, to disparate access to healthcare. Provider-to-population ratios are a primary measure of workforce adequacy and distribution. Studies suggest that primary care physician-to-population ratios are associated with positive population health indicators including self-rated health, life expectancy, low birth weight rates, and lower all-cause cancer, heart disease, stroke and infant mortality rates (Chen, Roy, Haddix, \& Thacker, 2010; Macinko, Starfield, \& Shi, 2007; Shi et al., 2005; Shi et al., 2004; Shi et al., 2003). This finding has implications for improving frontier health outcomes through increased access to primary healthcare providers. Of the 308 frontier counties in this study, only 214 had APRNs; 209 of those counties also had physicians.

Strategic workforce planning is hampered by the lack of reliable data on the numbers and types of health professionals currently employed in the frontier (Institute of Medicine, 2011). This study provides county-specific evidence regarding the presence of APRNs and physicians in frontier counties. Additionally, this study provides information regarding a potential frontier APRN workforce. Every frontier county included in this study had at least one RN. Rural workforce research indicates that grow-your-own recruitment strategies may yield better results than other recruitment methods (Walker, DeWitt, Pallant, \& Cunningham, 2012; Royston, 
Mathieson, Leafman, \& Ojan-Sheehan, 2012; Rural Health Research Center, 2014). The RNs residing in the frontier counties included in this study represent potential APRNs who may be more likely to stay and practice in their frontier communities if given an opportunity to advance their education without leaving their local areas.

Although county health indices were not available for many frontier counties, the STI rate was reported by all frontier counties. The significantly higher rate of reported STI cases in counties with APRNs is somewhat unsettling, but may reflect greater access to screening and, therefore reporting, or may be related to other factors not accounted for in this study. This finding may also correlate with the lower teen birth rate in counties with APRNs, as family planning clinics that screen for STIs also provide contraception services. Counties with APRNs also reported significantly lower premature death rates than counties without APRNs. While this finding may reflect the primary care and emergency care competencies that APRNs may bring to remote areas, it may also be related to other factors not accounted for in this study.

Results of this study indicate virtually no difference in the adult smoking rates between counties with and without APRNs. There was also no significant difference in the low birth weight percentage of residents in frontier counties with APRNs compared to those without APRNs. This finding may be related to frontier structural disparities that are unrelated to the presence of APRNs. In general, frontier counties have the worst self-reported health of all geographic designations; this finding can be explained in part by rural structural disadvantage, including higher rates of unemployment and lower educational levels (Monnat \& Pickett, 2011).

\section{Limitations}

While this study included data from 308 frontier counties representing $63 \%$ of the 486 frontier counties in the continental US, it was limited not only by variations in the numbers of 
frontier counties with available health outcome data, but also by variations in the types of indices reported. Missing outcome data from as many as 122 counties represented a major limitation in this study. Furthermore, APRN data utilized in this study was based on county of residence and may not represent employment location. Also, this study did not take into account the presence or absence of other providers such as physicians and physician assistants. It is possible that the 84 counties without APRNs or physicians may be served by visiting or rotating primary care providers; however, without conducting individual county surveys it is unlikely that this information is available. In addition, this comparative study did not account for social determinants of health, including income, education and race/ethnicity, which as noted above, have powerful impacts on population health (Lutfiyya, McCullough, Haller, Waring, Bianco \& Lipsky, 2012). Thus drawing causal inferences from the results of this study is not possible.

\section{Implications for Further Research}

Frontier residents experience a gap in accessing primary healthcare. With over five million people living in frontier counties, investigating reliable patient outcomes stemming from healthcare delivery models, particularly those which include APRNs, is a crucial step to bridging this gap.

Population health outcome data are limited in many frontier areas. As Rural Accountable Care Organizations develop in response to the Affordable Care Act, there may be greater opportunities to gather reliable, electronic data on frontier populations (Kutscher, 2013). Consistent reliable data would enhance research with populations in both frontier and rural areas.

Research addressing frontier healthcare and delivery is challenging due to methodological and statistical issues which include: small sample sizes, social/cultural issues, and inherent diversity among rural/frontier communities (Bigbee \& Lind, 2007). Therefore, qualitative studies 
that illustrate the impact of APRN presence on the delivery of frontier healthcare could be informative.

Definitional inconsistencies also make research with frontier populations challenging (Bigbee \& Lind, 2007). Rurality, specifically frontier areas, is defined in a variety of ways (Hart, 2012). Much of the information regarding frontier health and healthcare has been ferreted out of rural health research and may not accurately represent frontier communities. As noted earlier, larger frontier counties may contain urban or metropolitan population centers. Data from population centers may potentially skew aggregate county population data. Utilizing health outcome data based on zip-code rather than county designation may provide more accurate frontier data (Inagami, Gao, Karimi, Shendge, Probst, \& Stone, 2016; Knapp \& Hardwick, 2000; Wang, Ponce, Wang, Opsomer, \& Yu, 2015).

A recently published study regarding health system challenges in America's frontier areas found significantly fewer primary care physicians practicing in frontier versus non-frontier counties despite a higher need for primary care services (Nayar, Yu, \& Apenteng, 2013). The researchers did not take into account the presence of APRNs serving frontier counties although they recommended the use of APRNs and PAs as a solution to some of the disparities. Research into the specific contributions made by APRNs in both rural and frontier communities would inform healthcare policy.

The APRN role was conceptualized to provide patient care in underserved areas (Ford \& Silver, 1967), however, it would appear that few APRNs have ventured into the frontier. Research into effective recruitment and retention strategies targeted specifically at frontier areas, is warranted (Grobler, Marais, \& Mabunda, 2015). The grow-your-own recruitment and retention concept has implications for nurse educators as education has long been a recognized determinant 
of the availability and distribution of the nursing workforce. Research into best educational practices to prepare frontier RNs to provide advanced practice care in their local communities is a priority.

\section{Conclusion}

Residents in U.S. frontier communities represent a small but vulnerable population owing to disparate access to healthcare services. Despite federal incentives to promote the use of APRNs in rural and frontier settings, there is a lack of APRN presence in some U. S. frontier counties. More APRNs need to heed the call to improve population health in frontier areas of the U.S.) The RNs residing in the frontier counties included in this study represent potential APRNs who may be more likely to stay and practice in their frontier communities if given an opportunity to advance their education without leaving their local areas. This study provided insight into the distribution of APRNs in U.S. frontier counties.

Although limited by sporadic reporting of frontier health outcomes, results of this study indicate that frontier residents who have access to health care, regardless of type of provider, are likely to have better health outcomes than frontier counties without access to medical care. This highlights the necessity for improved reporting systems to garner reliable data that could support evidence-based models for healthcare provision in U.S. frontier communities.

\section{References}

American Association of Nurse Practitioners. State Regulatory Map. Retrieved from https://www.aanp.org/images/documents/state-leg-reg/stateregulatorymap.pdf

Bardach, S., Tarasenko, Y. \& Schoenberg, N. (2011). The role of social support in multiple morbidity: Self-management among rural residents. Journal of Health Care for the Poor and Underserved, 22(3), 756-771. https:/doi.org/10.1111/j.1748-0361.2012.00411.x 
Befort, C, Nazir, N., \& Perri, M. (2012). Prevalence of obesity among adults from rural and urban areas of the United States: Findings from NHANES (2005-2008). The Journal of Rural Health, 28(4), 392-397. http://dx.doi.org/10.1111/j.1748-0361.2012.00411.x

Bhuyan, S., Wang, Y., Opoku, S., \& Lin, G. (2013). Rural-urban differences in acute myocardial infarction mortality: Evidence from Nebraska. Journal of Cardiovascular Disease Research, 4, 209-213.

Bigbee, J., Evans, S., Lind, B., Perez, S., Jacobo, L., \& Geraghty, E. (2014). RN-to population ratio and population health: A multifactorial study. Journal of Nursing Regulation, 5(1), 17. https:/doi.org/10.1016/S2155-8256(15)30094-6

Bigbee, J. \& Lind, B. (2007). Methodological challenges in rural and frontier nursing research. Applied Nursing Research, 20, 104-106. https:/doi.org/10.1016/j.apnr.2007.01.001

Brooten, D., \& Youngblut, J. (2006). Nurse dose as a concept. Journal of Nursing Scholarship, 38(1), 94-99. https:/doi.org/10.1111/j.1547-5069.2006.00083.x

Brooten, D., Youngblut, J., Deosires, W., Singhala, K., \& Guido-Sanz, F. (2012). Global considerations in measuring effectiveness of advanced practice nurses. International Journal of Nursing Studies, 49(7), 906-912. https:/doi.org/10.1016/j.ijnurstu.2011.10.022

Brooten, D., Youngblut, J., Kutcher, J., \& Bobo, C. (2004). Quality and the nursing workforce: APNs, patient outcomes and health care costs. Nursing Outlook, 52(1), 45-52. http://dx.doi. $\underline{\operatorname{org} / 10.1016 / \text { j.outlook.2003.10.009 }}$

Brown, D. \& Schafft, K. (2011). Rural People and Communities in the 21st Century: Resilience \& Transformation. Polity Press: Malden, MA. 
Chen, Z., Roy,K., Haddix, A., \& Thacker, S. (2010). Factors associated with differences in mortality and self-reported health across states in the United States. Health Policy, 94(3), 203-210. https:/doi.org/10.1016/j.healthpol.2009.09.011

Cole, A., Jackson, J., \& Doescher, M. (2012). Urban-rural disparities in colorectal cancer screening: cross-sectional analysis of 1998-2005 data from the Centers for Disease Control's behavioral risk factor surveillance study. Cancer Medicine, I(3), 350-356. https:/doi.org/10.1002/cam4.40

Department of Health and Human Services. (2013). Rural Health clinic. (ICN 006398).

Earle-Richardson, G., \& Earle-Richardson, A. (1998). Commentary from the front lines: Improving the National Health Corps' use of medical providers. The Journal of Rural Health, 14(2), 91-97. https:/doi.org/10.1111/j.1748-0361.1998.tb00609.x

Ford, L., \& Silver, H. (1967). Expanded role of the nurse in child care. Nursing Outlook, 15, 4345.

Frontier Education Center. (2000). Geography of frontier America, The view at the turn of the century. Retrieved from http://frontierus.org/geography-of-frontier-america-the-view-atthe-turn-of-the-century/

Grobler, L., Marais, B., \& Mabunda, S. (2015). Interventions for increasing the proportion of health professionals practicing in rural and other underserved areas. Cochrane Database of Systemic Reviews,6, Article No:CD005314 https:/doi.org/10.1002/14651858.CD00531 $\underline{4 . p u b 3}$

Hale, N., Bennett, K., \& Probst, J. (2010). Diabetes care and outcomes: Disparities across rural America. Journal of Community Health, 35(4), 365-374. http://dx.doi.org/10.1007/s10900$\underline{010-9259-0}$ 
Hart, G. (2012). Frontier/Remote, Island, and Rural Literature Review (pp. 1-37): Center for Rural Health, University of North Dakota. Retrieved from https.//ruralhealth.und.edu/pdf/ frontierreview.pdf

Inagami, S., Gao, S., Karimi, H., Shendge, M., Probst, J., \& Stone R. (2016). Adapting the Index of Relative Rurality (IRR) to estimate rurality at the zip code level: A rural classification system in health services research. Journal of Rural Health, 32(2), 219-227. https:/doi.org $\underline{/ 10.1111 / \mathrm{jrh} .12148}$

Institute of Medicine (US). Committee on the Robert Wood Johnson foundation initiative on the future of nursing. (2011). The Future of Nursing: Leading change, Advancing Health. National Academies Press.

Jackson, B, Coultas, D., Suzuki, S., Singh, K., \& Bae, S. (2013). Rural-urban disparities in quality of life among patients with COPD. The Journal of Rural Health, 29(s1), s62-s69. https:/doi.org/10.1111/jrh.12005

Johnson, K. (2006). Demographic Trends in Rural and Small America. Durham, N: Carsey Institute, University of New Hampshire. Retrieved from http://scholars.unh.edu/cgi/viewc ontent.cgi?article $=1004 \&$ context $=$ carsey

Jones, R., Fly, M., Talley, J., Cordell, H. (2003). Green migration into rural America: the new frontier of environmentalism? Society \& Natural Resources, 16(3), 221-238. https:/doi. org $/ 10.1080 / 08941920309159$

Kaplan, L., Skillman, S., Fordyce, M., McMenamin, P. \& Doescher, M. (2012). Understanding APRN distribution in the United States using NPI data. The Journal for Nurse Practitioners, 8(8), 626-635. http://dx.doi.org/10.1016/j.nurpra.2012.05.022 
Knapp, K., \& Hardwick, K. (2000). The availability and distribution of dentists in rural zip codes and primary care health professional shortage areas (PC-HPSA) zip codes: Comparison with primary care providers. Journal of Public Health Dentistry, 60(1), 43-48. https:/doi.org/10.1111/j.1752-7325.2000.tb03291.x

Kulshreshtha, A., Goyal, A., Veledar, E., \& Vaccarino, V. (2014). Urban-rural differences in coronary heart disease mortality in the United States: 1999-2009. Public Health Reports, $129,19-29$.

Kutscher, B. (2013). Shift to coordinated care. Qualifying for ACOs, a tough challenge for rurals. Modern Healthcare, 43(42), 28-29.

Lorah, P. A. (2000). Population growth, economic security, and cultural change in wilderness counties. Retrieved from http://www.fs.fed.us/rm/pubs/rmrs p015 2/rmrs p015 2 230 237.pdf

Lutfiyya, M, McCullough, J., Haller, I., Waring, S., Bianco, J., \& Lipsky, M. (2012). Rurality as a root or fundamental social determinant of health. Disease-a-Month, 58(11), 620-628. http://dx.doi.org/10.1016/j.disamonth.2012.08.005

Macinko, J., Starfield, B., \& Shi, L. (2007). Quantifying the health benefits of primary care physician supply in the United States. International Journal of Health Services, 37(10), 111126. https:/doi.org/10.2190/3431-G6T7-37M8-P224

McCall-Hosenfeld, J., \& Weisman, C. (2011). Receipt of preventive counseling among reproductive-aged women in rural and urban communities. Rural and Remote Health, 11(1), 1617.

McGranahan, D. (2003). How people make a living in rural America. Challenges for rural America in the twenty-first century, 135-151. 
Monk, D. (2007). Recruiting and retaining high-quality teachers in rural areas. The Future of Children, 17(1), 155-174. https:/doi.org/10.1353/foc.2007.0009

Monnat, S., \& Pickett, C. (2011). Rural/urban differences in self-rated health: Examining the roles of county size and metropolitan adjacency. Health \& Place, 17, 311-319. https:/doi.org/10.1016/j.healthplace.2010.11.008

Nayar, P., Yu, F., \& Apenteng, B. (2013). Frontier America's health system challenges and population health outcomes. The Journal of Rural Health, 29(3), 258-265. https:/doi.org/ $\underline{10.1111 / \mathrm{j} .1748-0361.2012 .00451 . \mathrm{x}}$

Nguyen-Pham, S., Leung, J., \& McLaughlin, D. (2014). Disparities in breast cancer stage at diagnosis in urban and rural adult women: A systematic review and meta-analysis. Annals of Epidemiology, 24(3), 228-235. http://dx.doi.org/10.1016/j.annepidem.2013.12.002

Pathman, D., \& Konrad, T. (2012). Growth and changes in the National Health Service Corps (NHSC) workforce with the American recovery and reinvestment act. The Journal of the American Board of Family Medicine, 25(5), 723-733. https:/doi.org/10.3122/jabfm .2012 .05 .110261

Rayburn, W., Richards, M., \& Elwell, E. (2012). Driving times to hospitals with perinatal care in the United states. Obstetrics \& Gynecology, 119(3), 611-616. https:/doi.org/10.1097/AOG. $\underline{0 \mathrm{~b} 013 \mathrm{e} 318242 \mathrm{~b} 4 \mathrm{cb}}$

Ricketts, T., Johnson-Webb, K., \& Taylor, P. (1998). Definitions of Rural: A Handbookfor Health Policy Makers and Researchers. Office of Rural Health Policy.

Royston, P., Mathieson, K., Leafman, J., \& Ojan-Sheehan, O. (2012). Medical student characteristics predictive of intent for rural practice. Rural and Remote Health 12: 2107. Retrieved from http://www.rrh.org.au 
Rural Health Information Hub. How much of the U.S. is Frontier? Retrieved from https://www.ruralhealthinfo.org/topics/frontier

Rural Health Research Center. Support for Rural Recruitment and Practice among U.S. Nurse Practitioner Education Programs. Policy Brief \#147, May, 2014. http://depts.washington. $\underline{\text { edu/uwrhrc/uploads/RHRC PB147 Skillman.pdf }}$

Shi, L., Macinko, J., Starfield, B., Politzer, R., Wulu, J., \& Xu, J. (2005). Primary care, social inequalities and all-cause, heart disease and cancer mortality in US counties: A comparison between urban and non-urban areas. Public Health Reports, 119(8), 699-710.

Shi, L., Macinko, J., Starfield, B., Wulu, J., Regan, J., \& Politzer, R. (2003). The relationship between primary care, income inequality, and mortality in US States, 1980-1995. Journal of the American Board of Family Practice 16(5), 412-422. https:/doi.org/ 10.1016/j.puhe.2004.12.007

Shi, L., Macinko, J., Starfield, B., Xu, J., Regan, J., Politzer, R., \& Wulu, J. (2004). Primary care, infant mortality, and low birth weight in the states of the USA. Journal of Epidemiology \& Community Health, 58(5), 374-380. https:/doi.org/10.3122/ jabfm.16.5.412

Singh, G. (2012). Rural-urban trends and patterns in cervical cancer mortality, incidence, stage, and survival in the United states, 1950-2008. Journal of Community Health, 37(1), 217-223. https:/doi.org/10.1007/s10900-011-9439-6

Singh, G., Azuine, R., Siahpush, M., \& Kogan, M. (2013). All-cause and cause-specific mortality among US youth: Socioeconomic and rural-urban disparities and international patterns. Journal of Urban Health, 90(3), 388-405. https:/doi.org/10.1007/s11524-012-9744-0 
Singh, G., \& Siahpush, M. (2014). Widening rural-urban disparities in all-cause mortality and mortality from major causes of death in the USA, 1969-2009. Journal of Urban Health, 91(2), 272-292. https:/doi.org/10.1007/s11524-013-9847-2

Stasa, H., Cashin, A., Buckley, T., \& Donoghue, J. (2014). Advancing advanced practice: Clarifying the conceptual confusion. Nurse Education Today, 34(3), 356-361 http://dx.doi.org/10.1016/j.nedt.2013.07.012

United States Department of Agriculture, Economic Research Service (2015). Rural America at a Glance: 2015 edition. http://www.ers.usda.gov/media/1952235/eib145.pdf

University of Wisconsin Population Health Institute. (2012). County Health Rankings 2012. Madison, WI. Retrieved from www.countyhealthrankings.org

Walker, J., DeWitt, D., Pallant, J., \& Cunningham, C. (2012). Rural origin plus a rural clinical school placement is a significant predictor of medical students' intentions to practice rurally: a multi-university study. Rural and Remote Health 12: 1908. Retrieved from http://www.rrh.org.au

Wang, Y., Ponce, N., Wang, P., Opsomer, J., \& Yu, H. (2015). Generating health estimates by zip code: A semiparametric small area estimation approach using the California health interview Survey. American Journal of Public Health, 105(12), 2534-2540. https:/doi.org/10.2105/AJPH.2015.302810

Weaver, K., Geiger, A., Lu, L., \& Case, L. (2013). Rural-urban disparities in health status among US cancer survivors. Cancer, 119(5), 1050-1057. https:/doi.org/10.1002/cncr.27840 Wells, E. \& Weisheit, R. (2004). Patterns of rural and urban crime: A county-level comparison. Criminal Justice Review, 29(1), 1-22. https:/doi.org/10.1177/073401680402900103 
Wood, R. (2008). Survival of Rural America: Small Victories and Bitter Harvests. Lawrence, KS: University Press of Kansas. 